\title{
Epithelial-to-mesenchymal transition markers are differentially expressed in epithelial cancer cell lines after everolimus treatment
}

\author{
BRYAN ÔRTERO PEREZ GONÇALVES ${ }^{1}$, WARNE PEDRO DE ANDRADE ${ }^{2,3}$, \\ LETÍCIA DA CONCEIÇÃO BRAGA $^{1}$, SÍLVIA LIGÓRIO FIALHO ${ }^{4}$ and LUCIANA MARIA SILVA ${ }^{1}$ \\ ${ }^{1}$ Cellular Biology, Research and Development Department, Ezequiel Dias Foundation, Belo Horizonte, \\ Minas Gerais 30510-010; ${ }^{2}$ Hematology and Oncology Nucleus, Grupo Oncoclinicas, Belo Horizonte, Minas Gerais 30140001; \\ ${ }^{3}$ Department of Obstetrics and Gynecology, School of Medicine, São Paulo State University, Botucatu, São Paulo 18618687; \\ ${ }^{4}$ Pharmaceutical Research and Development, Ezequiel Dias Foundation, Belo Horizonte, Minas Gerais 30510-010, Brazil
}

Received April 8, 2020; Accepted July 14, 2020

DOI: 10.3892/ol.2020.12019

\begin{abstract}
The epithelial-to-mesenchymal transition (EMT) is a phenomenon during which cancer epithelial cells undergo changes in plasticity and lose cell-cell adhesion with consequent remodeling of the extracellular matrix and development of mesenchymal characteristics. Long non-coding RNAs (lncRNAs) have been described as EMT modulation markers, becoming a promising target in the development of new therapies for cancer. The present study aimed to investigate the role of everolimus at $100 \mathrm{nM}$ as inductor of the EMT phenomenon in cell lines derived from human breast (BT-549), colorectal (RKO-AS45-1) and ovary (TOV-21G) cancer. The integrity of cellular junctions was monitored using an in vitro model of epithelial resistance. The results demonstrated that the EMT genes ZEBI, TWISTI and TGFB1 were differentially expressed in cells treated with everolimus compared with in untreated cells. IncRNA HOTAIR was upregulated posttreatment only in BT-549 cells compared with in untreated cells. After treatment with everolimus, the intensity of fluorescence of P-cadherin decreased, and that of fibronectin increased in RKO-AS45-1 and TOV-21G cells compared with control cells. The transepithelial electrical resistance at the RKO-AS45-1
\end{abstract}

Correspondence to: Mr. Bryan Ôrtero Perez Gonçalves or Dr Luciana Maria Silva, Cellular Biology, Research and Development Department, Ezequiel Dias Foundation, Belo Horizonte, 80 Conde Pereira Carneiro Street, Gameleira, Minas Gerais 30510-010, Brazil E-mail: bryangoncalves96@hotmail.com

E-mail: luciana.silva@funed.mg.gov.br

Abbreviations: CTCF, corrected total cell fluorescence; EMT, epithelial-to-mesenchymal transition; IncRNA, long non-coding RNA; HOTAIR, HOX transcript antisense RNA; RQ, relative quantification; TEER, transendothelial/transepithelial electrical resistance; $T G F B 1$, transforming growth factor $\beta 1 ; T W I S T 1$, twist family basic helix-loop-helix transcription factor $1 ; Z E B 1$, zinc finger E-box-binding homeobox 1

Key words: EMT, cancer, everolimus, HOTAIR, biomarker monolayer treated with everolimus started to decrease at $48 \mathrm{~h}$. The changes in the gene expression and epithelial resistance may confirm the role of everolimus in EMT.

\section{Introduction}

The epithelial-to-mesenchymal transition (EMT) is a phenomenon during which cancer epithelial cells undergo changes in plasticity and lose cell-cell adhesion with consequent remodeling of the extracellular matrix and acquisition of mesenchymal characteristics $(1,2)$. The EMT phenomenon is associated with carcinogenesis, metastasis and chemoresistance (3).

EMT is regulated by a complex signaling network that involves transcription factors such as zinc-finger enhancer binding protein (ZEB1/2), twist family basic helix-loop-helix transcription factor 1/2 (TWIST1/2) and transforming growth factor beta (TGF- $\beta$ ) family members (4). TWIST1 transcription factor decreases the expression levels of epithelial genes, such as E-cadherin, and increases the expression levels of mesenchymal genes, such as fibronectin; ZEB1 is another transcriptional factor that regulates E-cadherin expression, while TGFB1 changes the plasticity of epithelial cells and promotes the remodeling of extracellular matrix composition (4).

A large number of long non-coding RNAs (lncRNAs) have been described as EMT modulation markers, becoming a promising target in the development of new therapies for cancer, especially due to their tissue-specific expression $(5,6)$. One such lncRNA is HOX transcript antisense RNA (HOTAIR), which comprises $\sim 2.2 \mathrm{~kb}$ and contains six exons transcribed from the HOXC locus and is located on chromosome 12q.13.13 (5). High expression levels of HOTAIR are associated with a poor prognosis in various types of cancer, such as colorectal, ovary and breast cancer (3-7).

Everolimus belongs to a class of drugs known as selective inhibitors of mTOR, with a specific target in the mTORC1 signal transduction complex, and has demonstrated antitumor activity in breast cancer preclinical models and in clinical trials (8-12). However, it has been described in the literature that at a concentration of $100 \mathrm{nM}$, everolimus induces the EMT phenomenon $(11,12)$. 
The present study aimed to investigate the role of $100 \mathrm{nM}$ everolimus in EMT through morphological characterization of cell lines derived from human breast (BT-549), colorectal (RKO-AS45-1) and ovary (TOV-21G) cancer and by the evaluation of the mRNA expression of EMT regulators $Z E B 1$, TWISTI and TGFB1, and IncRNA HOTAIR. In addition, an in vitro model of transepithelial/transendothelial electrical resistance (TEER) monitoring was used as means of assessing the integrity of cellular junctions.

\section{Materials and methods}

Cell culture. Cell lines BT-549 (breast ductal carcinoma; HTB-122 ${ }^{\mathrm{TM}}$ ), TOV-21G (ovarian adenocarcinoma; CRL-11730 ${ }^{\mathrm{TM}}$ ), RKO-AS45-1 (colorectal carcinoma; CRL-2579 ${ }^{\mathrm{TM}}$ ) and WI-26 VA4 (lung fibroblast used as a control; CCL-95.1 ${ }^{\mathrm{TM}}$ ) were purchased from the American Type Culture Collection. The BT-549 cell line was cultured in RPMI-1640 medium (Sigma-Aldrich; Merck KGaA) supplemented with $10 \%$ fetal bovine serum (FBS; Gibco; Thermo Fisher Scientific, Inc.) inactivated at $56^{\circ} \mathrm{C}$ for $30 \mathrm{~min}, 1 \% 0.2 \mathrm{M} \mathrm{L}$-glutamine and $10 \mathrm{mg} / \mathrm{ml}$ bovine insulin (Sigma-Aldrich; Merck KGaA). The TOV-21G cell line was grown in high-glucose Dulbecco's modified Eagle's medium (Sigma-Aldrich; Merck KGaA) supplemented with 15\% FBS and 1\% 0.2 M L-glutamine, and the RKO-AS45-1 and WI-26 VA4 cell lines were cultured in RPMI-1640 medium supplemented with 10\% FBS and $1 \%$ 0.2 M L-glutamine. Cells were incubated at $37^{\circ} \mathrm{C}$ in a humidified atmosphere enriched with $5 \% \mathrm{CO}_{2}$. The experiments were carried out obeying a certain passage number (between passages 4 and 6).

Everolimus solubilization. Everolimus (molecular weight, $958.224 \mathrm{~g} / \mathrm{mol}$ ) was suspended in dimethyl sulfoxide (DMSO) to achieve a concentration of $1 \mathrm{mM}$; for all assays, the final concentration of $100 \mathrm{nM}$ diluted in culture medium was used.

Extraction of total RNA and reverse transcription. Total RNA was extracted from tumor cells in culture before and after treatment with everolimus at $100 \mathrm{nM}$ for $24 \mathrm{~h}$ and from the normal cell line WI-26 VA4 without treatment using the TRIzol ${ }^{\circledR}$ reagent (Invitrogen; Thermo Fisher Scientific, Inc.) according to the manufacturer's instructions. The quantification of the total RNA extracted from cells was performed using a Nanovue ${ }^{\mathrm{TM}}$ Plus Spectrophotometer. The integrity of the extracted total RNA was evaluated by $1 \%$ agarose gel electrophoresis. A total of $2 \mu \mathrm{g}$ total RNA was treated with the RNAse-Free DNase set (Qiagen), and complementary DNA (cDNA) synthesis was performed using the M-MLV Reverse Transcriptase ${ }^{\circledR}$ kit (Sigma-Aldrich; Merck KGaA), Oligo dT (Eurofins Scientific) and dNTPs (Promega Corporation) according to the manufacturer's instructions.

Quantitative PCR ( $q P C R)$. Transcript analysis of $Z E B 1$, TWISTl and TGFBl was performed by qPCR using PowerUp ${ }^{\mathrm{TM}}$ $\mathrm{SYBR}^{\circledR}$ Green Master Mix (Thermo Fisher Scientific, Inc.) according to the manufacturer's instructions. The primers used are shown in Table I. The TATA-binding protein (TBP) gene was used as the endogenous housekeeping gene. The reactions were subjected to specific amplification cycles (40 cycles of denaturation at $95^{\circ} \mathrm{C}$ for $15 \mathrm{sec}$ and annealing/elongation at $60^{\circ} \mathrm{C}$ for $1 \mathrm{~min}$ ) and the dissociation curve according to the manufacturer's instructions. The expression of lncRNA HOTAIR was evaluated using TaqMan ${ }^{\circledR}$ Non-Coding RNA assay (Applied Biosystems; Thermo Fisher Scientific, Inc.). TaqMan ${ }^{\circledR}$ Universal Master mix (Thermo Fisher Scientific, Inc.) was used according to the manufacturer's instructions, and $T B P$ and $18 S$ genes were used as endogenous controls, with the results normalized to the average of the endogenous controls. This assay was performed once in duplicate. Total RNA and cDNA-free samples were used as controls in each assay. Cycling and data collection were performed on a StepOne ${ }^{\mathrm{TM}}$ Real-Time PCR System (Applied Biosystems; Thermo Fisher Scientific, Inc.). Gene expression was quantified using the relative $2^{-\Delta \Delta C q}$ quantification method (13). In order to determine the relative changes in the mRNA expression levels of TGFB1, TWIST1 and ZEBI in the cells treated with everolimus compared with untreated samples, $\Delta \mathrm{Ct}$ values from three normalization controls were used: i) Untreated samples of each cell line; ii) untreated BT-549 samples; and iii) untreated WI-26 VA4 samples.

Fluorescence microscopy. The cell lines (BT-549, $5 \times 10^{4}$ cells/well; TOV-21G andRKO-AS45-1,2.5x10 4 cells/well) were seeded on Lab-Tek slides (Thermo Fisher Scientific, Inc.) and incubated overnight at $37^{\circ} \mathrm{C}$ in $5 \% \mathrm{CO}_{2}$. After treatment with $100 \mathrm{nM}$ everolimus for $24 \mathrm{~h}$, BT-549, TOV-21G and RKO-AS45-1 were fixed with $4 \%$ formaldehyde for $1 \mathrm{~h}$, permeabilized with $0.1 \%$ Triton $\mathrm{X}-100$ for $10 \mathrm{~min}$ and labeled with DAPI, Phalloidin and LysoTracker ${ }^{\circledR}$ Red DND-99 probes (Invitrogen; Thermo Fisher Scientific, Inc.) according to the manufacturer's instructions, all at room temperature. The labelling was assessed using an Axiovert 200M fluorescence microscope (Carl Zeiss AG) with AxioVision Rel. 4.8.2 software (Carl Zeiss AG). The fluorophores were read according to each emission spectrum (DAPI, $461 \mathrm{~nm}$; Phalloidin, $518 \mathrm{~nm}$; and LysoTracker, $590 \mathrm{~nm}$ ). To evaluate whether everolimus affected the cytoskeleton of the cells, the nuclei of 25 cells labeled with DAPI and Phalloidin were measured (in the same slide). Using ImageJ version 1.50i software (National Institutes of Health), a region of interest was drawn manually around each LysoTracker-labeled cell, and the corrected total cell fluorescence (CTCF) was calculated by subtracting the fluorescence intensity of the selected cell area multiplied by the mean bottom well fluorescence (background).

Immunofluorescence. The cell lines (BT-549, 5x10 4 cells/well; TOV-21G and RKO-AS45-1, 2.5x10 cells/well) were seeded on Lab-Tek slides (Thermo Fisher Scientific, Inc.) and incubated overnight at $37^{\circ} \mathrm{C}$ in $5 \% \mathrm{CO}_{2}$. Following 24-h treatment with $100 \mathrm{nM}$ everolimus, the cells were fixed with $4 \%$ formaldehyde solution for $1 \mathrm{~h}$, permeabilized with $0.1 \%$ Triton X-100 for $10 \mathrm{~min}$ and labeled for $45 \mathrm{~min}$ with anti-E-cadherin (1:50; cat. no. 610182; BD Biosciences), anti-P-cadherin (1:50; cat. no. 610228; BD Biosciences) and anti-fibronectin antibodies (1:50; cat. no. A21316; Invitrogen; Thermo Fisher Scientific, Inc.) according to the manufacturers' instructions, all at room temperature. After incubation, the wells were washed with 1 X PBS three times, and the wells incubated with 
Table I. Details of primers used for quantitative PCR.

\begin{tabular}{llr}
\hline Gene & \multicolumn{1}{c}{ Sequence $\left(5^{\prime} \rightarrow 3^{\prime}\right)$} & Concentration, nM \\
\hline$Z E B 1$ & F: TTACACCTTTGCATACAGAACCC & 300 \\
& R: TTTACGATTACACCCAGACTGC & 300 \\
TWIST1 & F: GTCCGCAGTCTTACGAGGAG & 300 \\
& R: GCTTGAGGGTCTGAATCTTGCT & 150 \\
$T G F B 1$ & F: AACTGCTTCCTGTATGGGGTC & 300 \\
$T B P$ & R: AAGGCGTCGTCAATGGACTC & 200 \\
& F: CGGCTACCACATCCAAGGAA & 250 \\
& R: GCTGGAATTACCGCGGCT & 250 \\
\hline
\end{tabular}

F, forward; R, reverse; TBP, TATA-binding protein; TGFB1, transforming growth factor $\beta 1$; TWIST1, twist family basic helix-loop-helix transcription factor 1; $Z E B 1$, zinc finger E-box-binding homeobox 1.

the primary antibodies against E/P-cadherin were incubated with a FITC-conjugated anti-mouse IgG secondary antibody (1:128; cat. no. F5262; Sigma-Aldrich; Merck KGaA), whereas the wells incubated with anti-fibronectin were incubated with an Alexa 594-conjugated anti-chicken IgG secondary antibody (1:500; cat. no. A32759; Invitrogen; Thermo Fisher Scientific, Inc.) for $2 \mathrm{~h}$, all at room temperature. After incubation, the wells were washed three times with $1 \mathrm{X}$ PBS, and the nuclei were labeled with DAPI. The markers were analyzed under the Axiovert 200M fluorescence microscope using AxioVision Rel. 4.8.2 software. The 25-cell CTCF in the same slide was also calculated using ImageJ software as aforementioned. The fluorescence intensity of the nuclei was subtracted from the integrated density obtained within the outline of each cell.

MTT assay. Cell viability in the presence of $100 \mathrm{nM}$ everolimus was determined using the 3-(4,5-dimethylthiazol2-yl)-2,5-diphenyltetrazolium bromide method (MTT) as previously described by Mitchell et al (14). Untreated cells and those treated with hydrogen peroxide were used as negative and positive controls, respectively. The absorbance measurement was performed using a spectrophotometer (SpectraMax ${ }^{\circledR}$ M5e; Molecular Devices, LLC) at $550 \mathrm{~nm}$. The viability of the treated cells was calculated by dividing the absorbance value of the treated cells by the mean of the untreated control multiplied by 100 .

Clonogenic assay. The clonogenic assay was performed as previously described by Franken et al (15). RKO-AS45-1 (500 cells) and TOV-21G (1,500 cells) cell lines were treated with $100 \mathrm{nM}$ everolimus and seeded in $60-\mathrm{mm}$ culture dishes in triplicate. The cells were incubated at $37^{\circ} \mathrm{C}$ for 7 days. Colonies with $\geq 50$ cells were counted. The plating efficiency (PE) was determined by dividing the mean number of colonies of the controls by the number of plated cells. The surviving fraction (SF) was calculated by dividing the mean of colonies formed after treatment by the number of plated cells and multiplying the result by the PE. The result was multiplied by $100 \%$. The colonies were analyzed with DAPI and Phalloidin probes as aforementioned.
Transepithelial electrical resistance measurement. RKO-AS45-1 cells were treated in individual wells with either: i) $1 \mu \mathrm{g}$ their own total RNA; ii) $700 \mathrm{ng} / \mathrm{ml} \mathrm{TGF-} \alpha$; or iii) $100 \mathrm{nM}$ everolimus, and seeded in RPMI-1640 medium supplemented with $10 \% \mathrm{FBS}, 100 \mathrm{U}$ penicillin and $100 \mu \mathrm{g}$ streptomycin in a Transwell ${ }^{\circledR}$ system (Corning, Inc.) with a $3-\mu \mathrm{m}$ polystyrene membrane and a growth area of $1.12 \mathrm{~cm}^{2}$. Cell resistance was measured using the Millicell ${ }^{\circledR}$ ERS 2 apparatus (EMD Millipore) at 0, 3, 24 and $48 \mathrm{~h}$. To obtain the correct resistance in Ohms, the resistance value of the wells with medium was subtracted from the resistance value of the wells with cells, and the correct resistance value was obtained by multiplying this with the membrane area. This experiment was carried out in biological triplicates.

Protein-protein interaction (PPI) network and molecular classification of the cell lines. The STRING database (version 10.5) was used to evaluate PPIs (16). Classification of the mutations in EMT genes evaluated in the present study was performed using the somatic mutation database COSMIC v85 (https://cancer.sanger.ac.uk/cosmic). The molecular classification of RKO, the parental cell line of RKO-AS45-1, was used due to the absence of the data for RKO-AS45-1 cells in the database.

Statistical analysis. Statistical analyses were performed with SPSS 20 software (IBM Corp.). Differences in gene expression and cell resistance between groups were analyzed using one-way ANOVA with the least significant difference post hoc test. The results of the microscopy assays were analyzed using the non-parametric Mann Whitney test. The results of the cell viability and clonogenic assays were evaluated using the Kruskal Wallis test followed by the least significant difference test. $\mathrm{P}<0.05$ was considered to indicate a statistically significant difference.

\section{Results}

Everolimus alters the transcription of the EMT regulators. The results of the qPCR analysis demonstrated that TGFB1 appeared to be upregulated in the RKO-AS45-1 and BT-549 
A

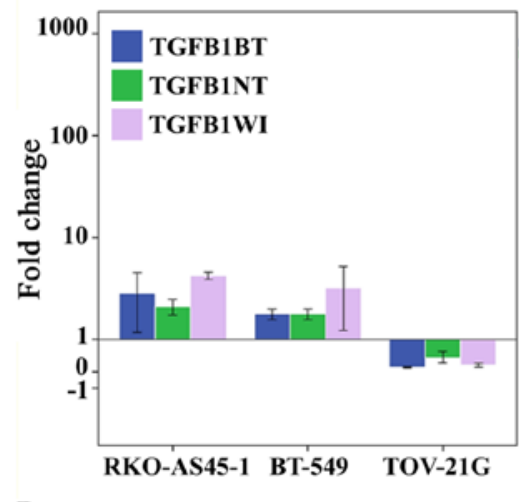

B

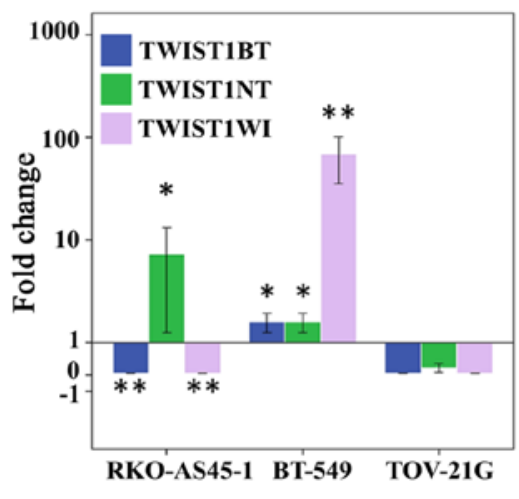

C



D HOTAIR

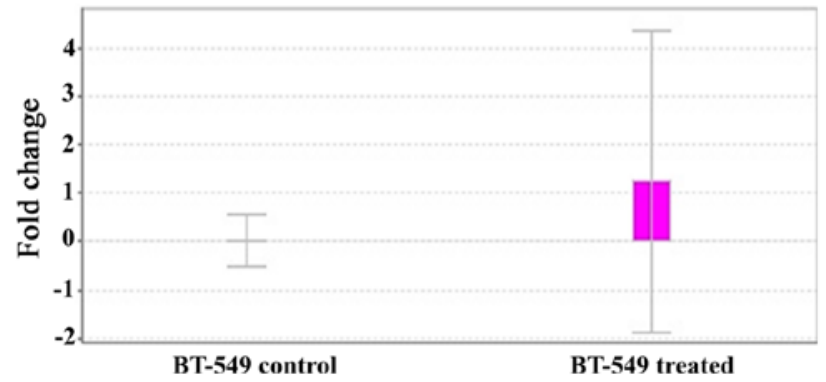

Figure 1. Everolimus changes the gene transcription of epithelial-to-mesenchymal transition regulators. (A-C) Evaluation of the mRNA expression of ZEB1, $T W I S T 1$ and TGFB1 by quantitative PCR. The results are presented as the fold-change compared with NT, BT and WI groups. (A) RQ of TGFB1 mRNA expression. (B) RQ of TWIST1 mRNA expression. (C) RQ of ZEB1 mRNA expression. n=2. (D) Evaluation of lncRNA HOTAIR expression in everolimus-treated BT-549 cells by quantitative PCR normalized to untreated BT-549 cells. ${ }^{*} \mathrm{P}<0.05 ;{ }^{* * *} \mathrm{P}<0.01$. NT, samples not treated with everolimus; BT, untreated sample of BT-549 cells; WI, untreated sample of WI-26 VA4 cells; TGFB1, transforming growth factor $\beta 1 ;$ TWIST1, twist family basic helix-loop-helix transcription factor 1; ZEB1, zinc finger E-box-binding homeobox 1; RQ, relative quantification.

cell lines treated with everolimus independently compared with all three types of normalization control, whereas in the TOV-21G cell line, TGFB1 appeared to be downregulated (Fig. 1A). However, these results were not statistically significant. Significant differences between TWIST1 RQs normalized to the three controls were observed in the RKO-AS45-1 and BT-549 cell lines following everolimus treatment (Fig. 1B). TWIST1 was downregulated in RKO-AS45-1 compared with untreated BT-549 and WI-26 VA4 cells, but upregulated compared with untreated RKO-AS45-1 cells. In BT-549 cells, TWIST1 was upregulated compared with all three normalization controls. In TOV-21G cells, TWIST1 appeared to be downregulated compared with the control, and no statistical differences were observed between the analyzed groups. The analysis of ZEBI RQ (Fig. 1C) demonstrated that the expression of its mRNA appeared to be downregulated in the three cell lines compared with that in untreated BT-549 cells, but upregulated in RKO-AS45-1 and TOV-21G cell lines compared with the respective untreated cell lines and WI-26 VA4. However, only the differences observed in the expression of $Z E B 1$ in TOV-21G were statistically significant.

IncRNA HOTAIR is upregulated in BT-549 cells after treatment with everolimus. Only the BT-549 triple negative breast cancer cell line demonstrated amplified lncRNA HOTAIR following treatment with everolimus (Fig. 1D).

Everolimus induces morphological changes in cell lines. In untreated BT-549 cells, extensive cytoplasmic projections were observed before exposure to everolimus (white arrow; Fig. 2A). Analyses of RKO-AS45-1 (Fig. 2C) and TOV-21G (Fig. 2E) nuclei did not reveal any significant changes in cell size. However, after treatment with everolimus, the RKO-AS45-1 cells exhibited cytoplasmic extensions (white circle) similar to those of untreated BT-549 cells. BT-549 cells were negative for the epithelial markers E/P-cadherin (Fig. 2B), but positive for the mesenchymal marker fibronectin (Fig. 3). RKO-AS45-1 and TOV-21G cells were positive for E/P-cadherin (Fig. 2D and F, respectively), but most of the RKO-AS45-1 and TOV-21G cells were negative for fibronectin (Fig. 3).

Following treatment with everolimus, a loss of BT-549 cell cytoskeleton integrity was observed, as demonstrated by the CTCF analysis of cell nuclei measured (Fig. 4A). No statistical differences in lysosome labeling were observed between the untreated and everolimus-treated groups of BT-549 cells. Analysis of the lysosomal profile revealed a significant decrease in the CTCF of RKO-AS45-1 cells and a significant increase in the CTCF of TOV-21G cells treated with everolimus compared with untreated cells (Fig. 4A). After treatment with everolimus, no significant changes were observed for E/P-cadherin or fibronectin CTCF in the BT-549 cell line (Fig. 4B-D). Treatment with everolimus also did not affect the expression of E-cadherin in RKO-AS45-1 and TOV-21G cells. However, a decrease in P-cadherin expression and an increase in fibronectin expression were observed in the RKO-AS45-1 and TOV-21G cell lines treated with everolimus compared with the untreated control cells (Fig. 4B-D). 
A



C

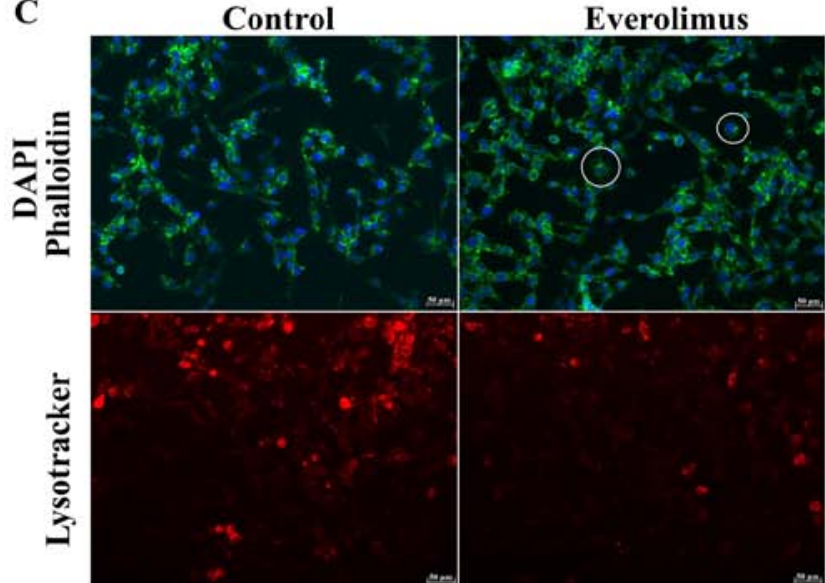

$\mathbf{E}$

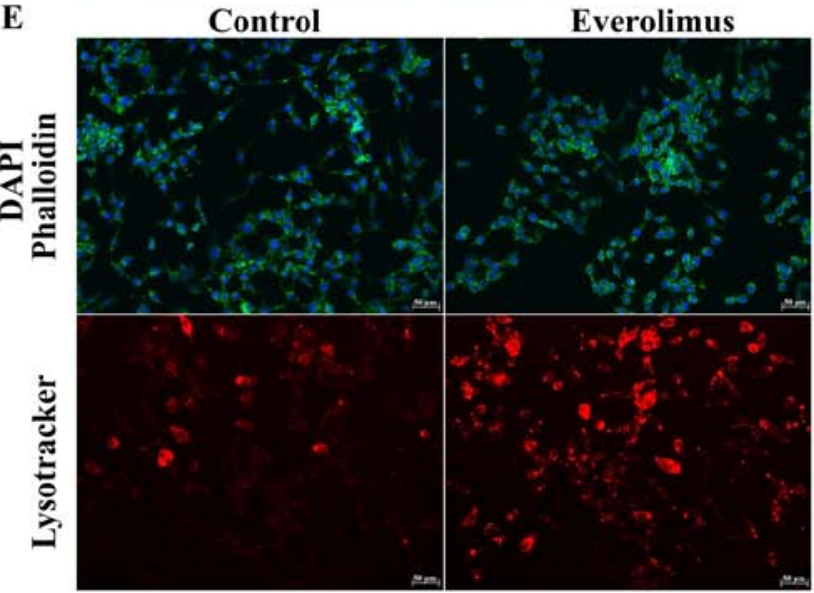

B

D

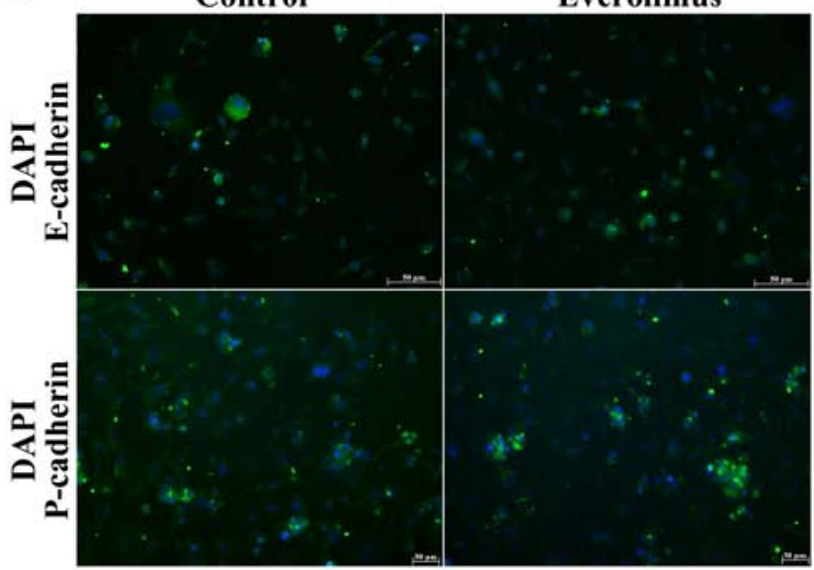

Control

Everolimus

Control

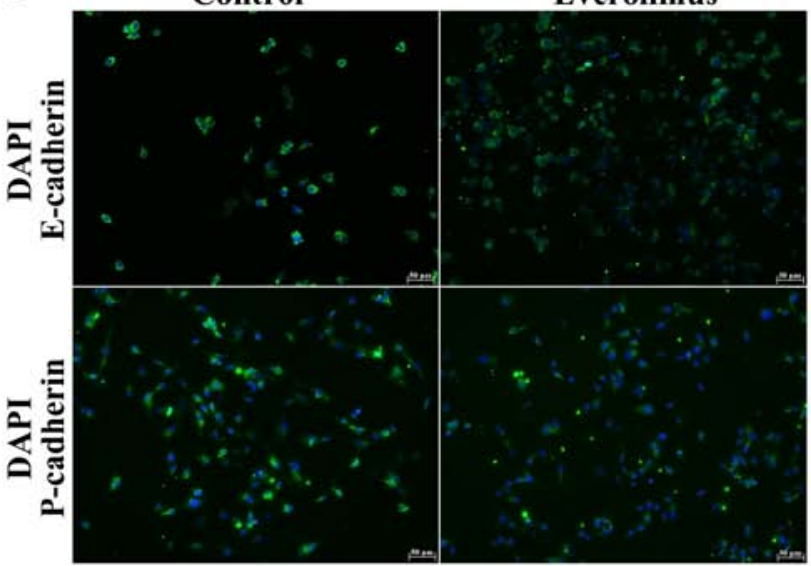

F

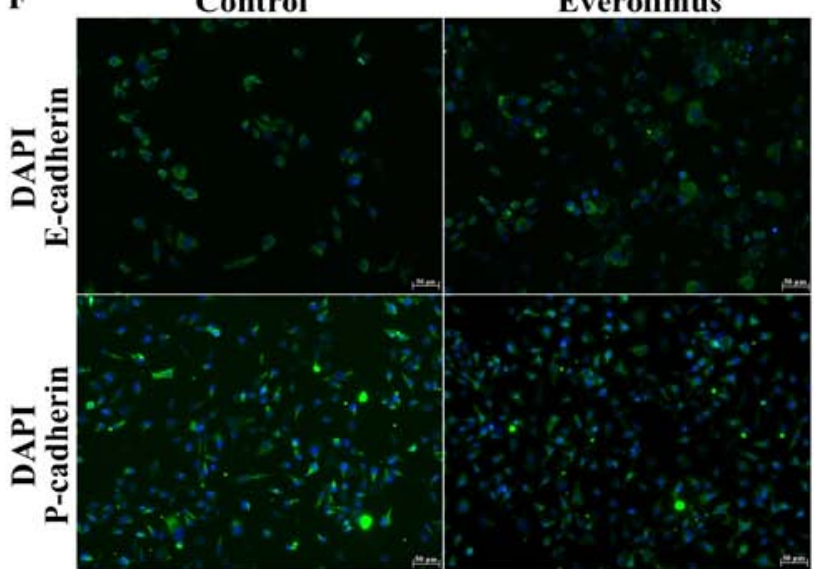

Figure 2. Morphological characterization of cells treated with everolimus by fluorescence microscopy and immunofluorescence. (A-F) Cells treated with 0 or $100 \mathrm{nM}$ everolimus labeled with DAPI, (A, C and E) Phalloidin and LysoTracker Red DND 99 or (B, D and F) anti E/P-cadherin. (A) In the BT-549 cell line, following treatment with everolimus, filopodia (white arrow) were diminished. (B) Immunofluorescence analysis of E/P cadherin epithelial markers in the BT-549 cell line. (C) RKO-AS45-1 exhibited cytoplasmic extensions similar to those of BT-549 before everolimus treatment (white circles). (D) Immunofluorescence analysis of E/P cadherin in RKO-AS45-1 cells. (E) Morphological characterization by fluorescence microscopy of the TOV-21G cell line. (F) Immunofluorescence analysis of E/P cadherin in TOV-21G cells. Magnification, x20. Scale bar, $50 \mu \mathrm{M}$.

Everolimus decreases proliferation in BT-549 cells. The MTT assay was performed to evaluate the survival of BT-549, RKO-AS45-1 and TOV-21G cells following treatment with everolimus to determine whether the $100 \mathrm{nM}$ concentration of the drug may lead to an increase in cell proliferation (Fig. 5A). The viability of RKO-AS45-1 and TOV-21G cells treated with everolimus was higher compared with that of the positive and negative controls; however, the differences between the everolimus-treated and untreated groups were not significant. By contrast, the viability of BT-549 cells after treatment with everolimus was significantly lower compared with that of the untreated controls.

Everolimus induces clonogenic survival. RKO-AS45-1 cells treated with $100 \mathrm{nM}$ everolimus were observed to form colonies that were farther distanced from each other compared 


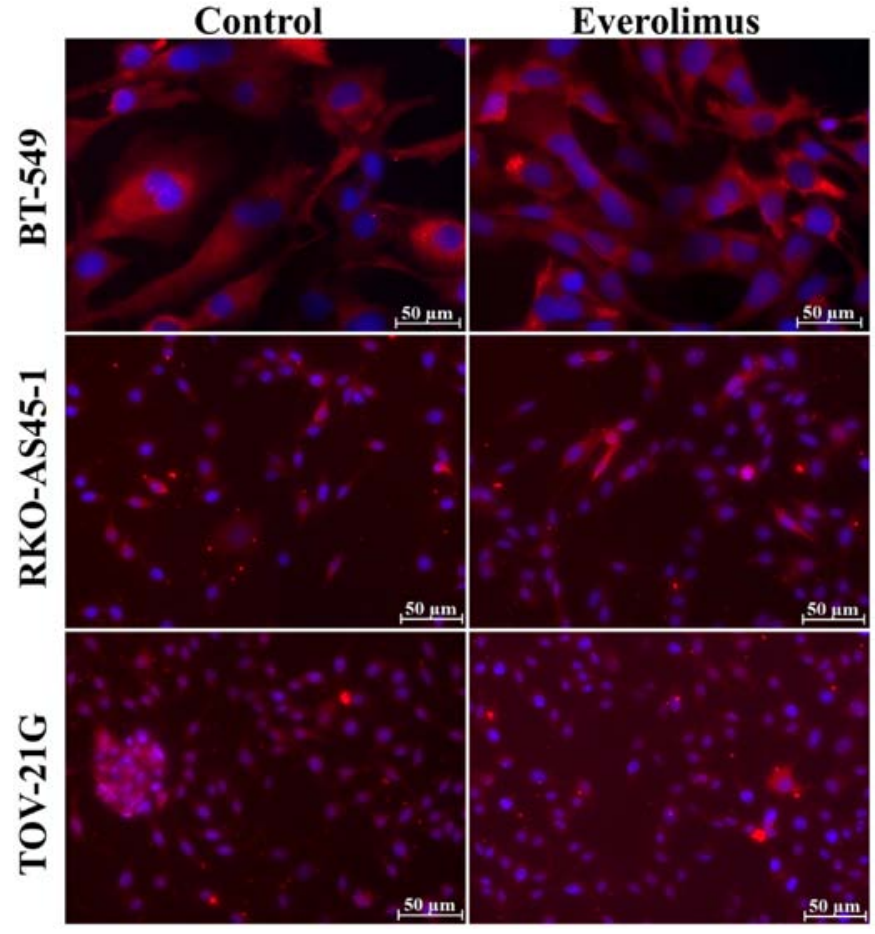

Figure 3. Immunofluorescence analysis of the mesenchymal marker fibronectin. Cells were treated with 0 or $100 \mathrm{nM}$ everolimus, and the nuclei were labeled with DAPI. Magnification, x20. Scale bar, $50 \mu \mathrm{M}$.

with those formed by untreated cells (Fig. 5B). A high SF was observed, especially for TOV-21G cells, but the difference between the treated and untreated cells was not statistically significant (Fig. 5C).

Everolimus induces changes in TEER. According to the aforementioned results, RKO-AS45-1 cells exhibit more EMT characteristics after treatment with $100 \mathrm{nM}$ everolimus. Therefore, this cell line was selected for the TEER assay. The TEER of the RKO-AS45-1 monolayer started to decrease at $48 \mathrm{~h}$ post-treatment with TGF- $\alpha$ and everolimus, indicating changes in the integrity of the cell monolayer. However, no significant differences were observed among the treatments (Fig. 5D).

PPIs and classification of EMT target mutations. The analysis in the STRING database was performed to explore the PPIs of the EMT targets evaluated in the present study (Fig. 6). No mutations were identified in the EMT genes in BT-549 and TOV-21G cells (Table II). For the RKO cell line, missense mutations were identified in the TGFBl and P-cadherin genes, and nonsense mutations were identified in $Z E B 1$.

\section{Discussion}

EMT is a highly orchestrated event involving a series of changes that lead to the loss of epithelial cell characteristics, such as a decrease in adhesion molecules and apical-basal polarity, and to the acquisition of a mesenchymal phenotype and the capacity of invasion and migration through the remodeling of the extracellular matrix, with the release of metalloproteases and expression of fibronectin, laminin and collagen; therefore, the EMT phenomenon is closely associated with carcinogenesis, metastasis and chemoresistance (17).

In TGFB1, TWISTI and ZEB1 relative gene expression assays in the present study, untreated BT-549 and WI-26 VA4 samples were used as normalization controls. The BT-549 cell line exhibits mesenchymal characteristics, and are cells that have undergone EMT (18). WI-26 VA4 cells are fibroblasts; therefore, they have a true mesenchymal phenotype (19).

TWIST transcription factors serve an important role in the EMT phenomenon, especially in cancer cells; TWIST decreases the expression of epithelial genes, such as E-cadherin, and promotes the expression of mesenchymal genes, such as fibronectin (20). In addition to TWIST1, ZEB1 is another transcriptional factor that regulates E-cadherin expression by binding to regions known as enhancers, thus decreasing the transcription efficiency of this gene (20). In addition, the TGFB1 protein is involved in EMT, as it changes the plasticity of epithelial cells and promotes the remodeling of the extracellular matrix composition, thus stimulating the expression of proteins such as collagen and fibronectin, as well as being involved in the differentiation and maintenance of cancer stem cells (CSCs) $(21,22)$.

Previous studies have demonstrated that $T G F B 1$ is capable of inducing EMT in colorectal and breast cancer cell lines (4,23-25). In the present study, the upregulation of TGFB1 mRNA expression was observed in RKO-AS45-1 and BT-549 cells after treatment with everolimus compared with all three normalization controls, although these results were not statistically significant. Wang et al (26) have demonstrated that overexpression of TWIST1 induces the EMT phenomenon in breast cancer cells. In addition, TWIST1 has been described as a potential biomarker of poor prognosis, chemoresistance, metastasis and disease recurrence in colorectal cancer (26-28). Thus, the results of the present study indicating the upregulation of TWIST1 in breast and colorectal cancer cells following everolimus treatment compared with that in untreated cells reinforces the hypothesis that everolimus acts as an inducer of the EMT. The upregulation of ZEBI expression in RKO-AS45-1 and TOV-21G cells after treatment compared with that in untreated cells observed in the present study was also in agreement with the hypothesis that everolimus triggers the in vitro EMT phenomenon. The downregulation of TGFB1 and TWIST1 in TOV-21G cells compared with all three normalization controls may indicate that the EMT phenomenon in these cells was dependent on other pathways different from those triggered by these targets.

Gupta et al (29) have demonstrated that IncRNA HOTAIR is associated with metastasis in breast cancer. HOTAIR interacts with the polycomb repressive complex 2 and causes repression of epithelial markers such as E-cadherin via H3K27 trimethylation, thereby promoting EMT and inducing cancer stem cell features (29).

In the BT-549 cell line, which is representative of a basal-like subtype of triple-negative breast tumors characterized by lack of treatment and aggressiveness $(18,30,31)$, high expression levels of HOTAIR may be considered a poor prognostic feature (29). According to Padua et al (32), cells that express high levels of HOTAIR also exhibit high expression levels of EMT-inducing genes, such as ZEB1, TWIST1 and TGFB1. 
Table II. Classification of mutations in EMT targets in cell lines used in the present study according to the COSMIC database.

\begin{tabular}{llr}
\hline Cell line & \multicolumn{1}{c}{ Mutation } & Type \\
\hline BT-549 & Not found & Substitution nonsense \\
RKO & ZEB1 (ENSG00000148516) & Substitution missense \\
& TGFB1 (ENST00000221930) & Substitution missense \\
TOV-21G & $C D H 3$ (ENSG00000062038) &
\end{tabular}

EMT, epithelial-to-mesenchymal transition; TGFB1, transforming growth factor $\beta 1$; ZEB1, zinc finger E-box-binding homeobox 1 ; $C D H 3$, P-cadherin.
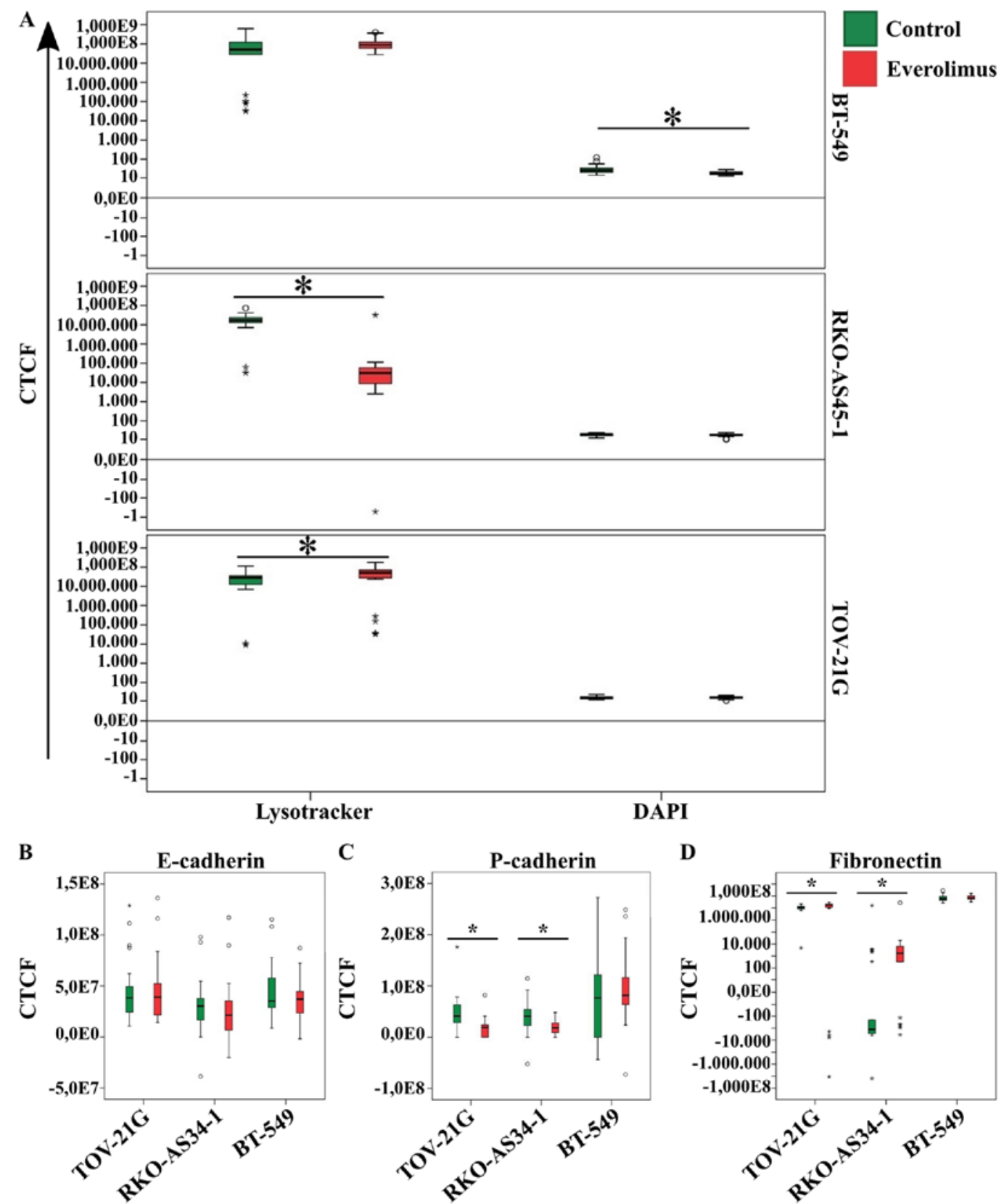

Figure 4. Analysis of the CTCF profiles of the BT-549, RKO-AS45-1 and TOV-21G cell lines treated with everolimus compared with untreated cells. (A) Following everolimus treatment, significant changes were observed in BT-549 cell size; however, there were no changes in the lysosomal CTCF. RKO-AS45-1 and TOV-21G cells exhibited no changes in the cell size, but a decrease in lysosomal CTCF was observed in RKO-AS45-1 cells, and an increase in lysosomal CTCF was observed in TOV-21G cells. (B-D) No significant changes in the E/P cadherin profile and fibronectin were observed in BT-549 cells following everolimus treatment; in RKO-AS45-1 and TOV-21G cells, there were no changes in the E-cadherin profile; however, there a decrease in the $\mathrm{P}$-cadherin level and an increase in fibronectin were observed after everolimus treatment. $\mathrm{n}=25 .{ }^{*} \mathrm{P}<0.05$. CTCF, corrected total cell fluorescence. 
A

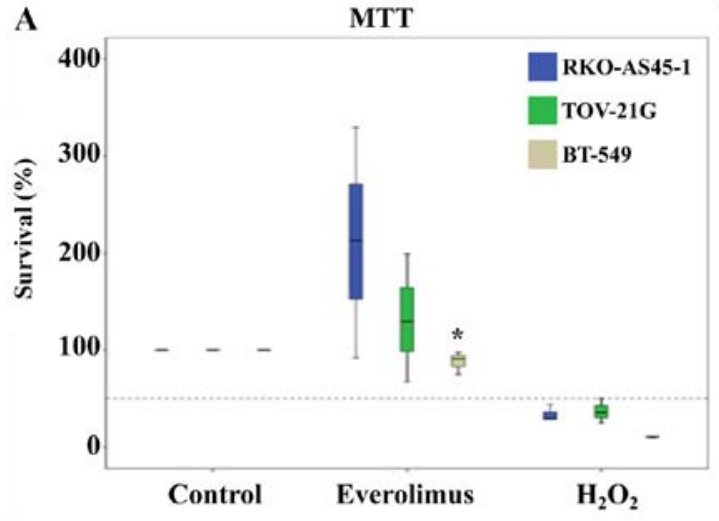

C

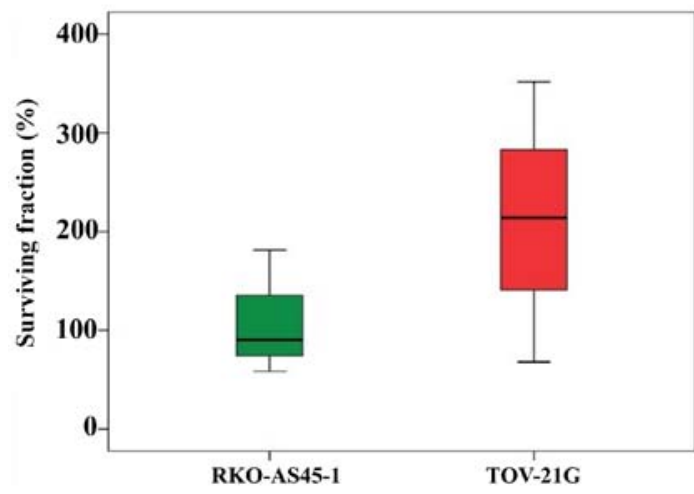

B

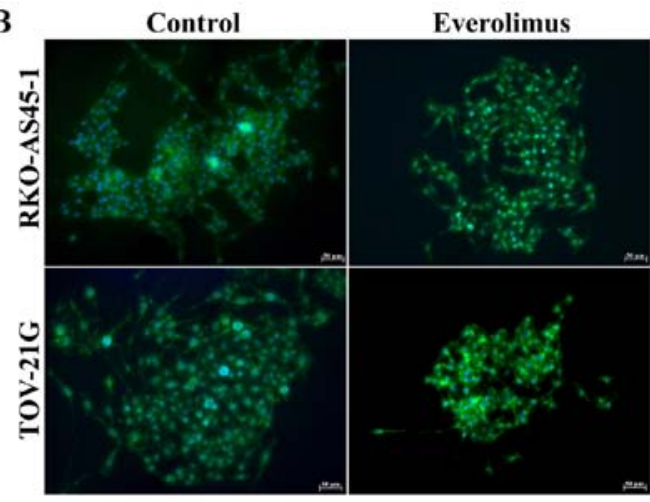

D

Transepithelial/transendothelial electrical resistance (TEER)

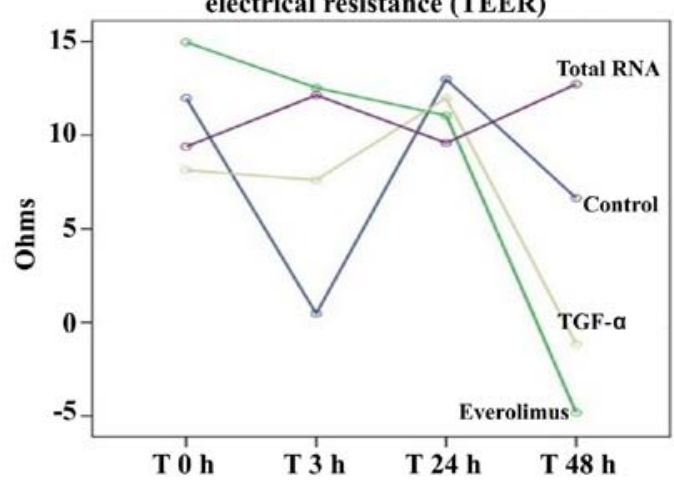

Figure 5. Cell viability, clonogenic cell survival assay and transepithelial resistance analysis. (A) The viability of BT-549 (beige bars), RKO-AS45-1 (blue bars) and TOV-21G (green bars) cells following treatment with $100 \mathrm{nM}$ everolimus was analyzed by the MTT method and normalized to untreated cells (control). (B) Microscopy analysis of the colonies formed by RKO-AS45-1 and TOV-21G cells treated with 0 or $100 \mathrm{nM}$ everolimus, and labeled with DAPI/Phalloidin. (C) Surviving fraction of RKO-AS45-1 and TOV-21G cells treated with 0 or $100 \mathrm{nM}$ everolimus. No significant differences were observed. Untreated cells were used as the control. (D) Transepithelial resistance profile of RKO-AS45-1 cells. No significant differences were observed. Untreated cells were used as control. $\mathrm{n}=3$. ${ }^{*} \mathrm{P}<0.05$ vs. control.
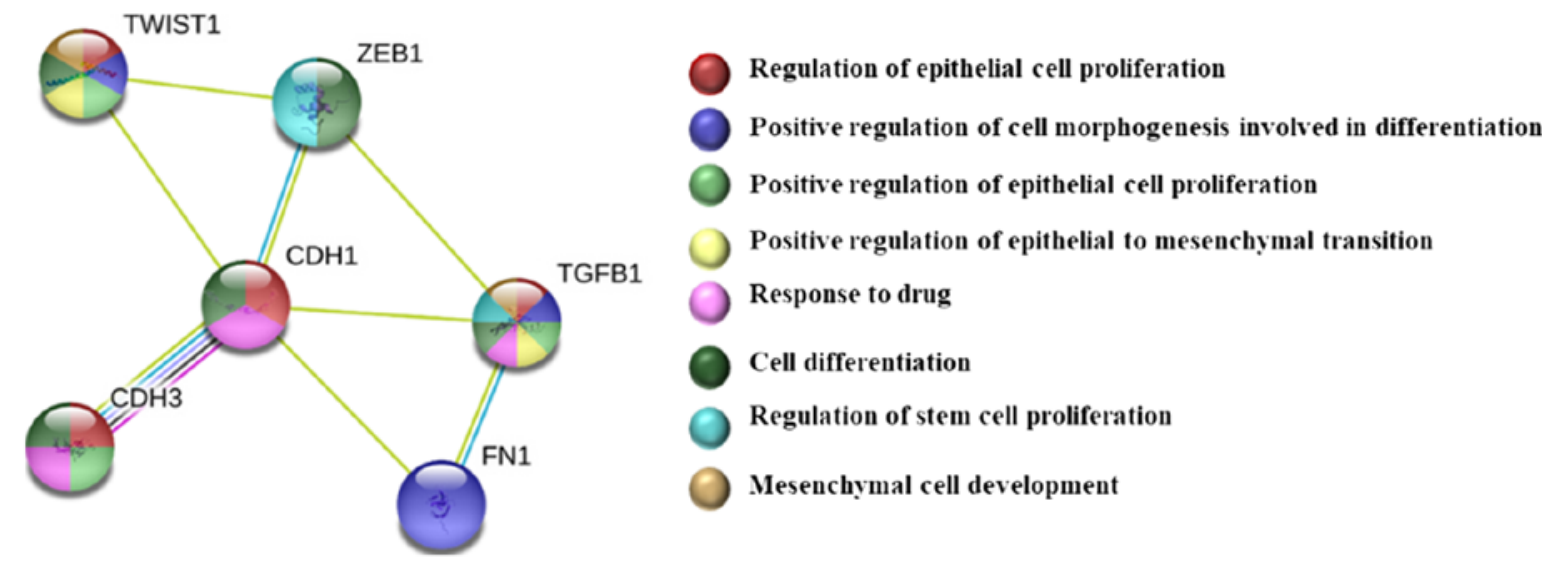

Figure 6. Protein-protein interaction analysis by STRING. The data were extracted from curated databases (turquoise line) or determined experimentally (pink). The light purple line represents protein homology. The yellow line represents text-mining. Co-expressed proteins are linked by black line. The color of the node denotes the pathway in which proteins are involved.

The occurrence of filopodia (projections of the cytoplasm described in the literature as structures rich in actin filaments that contribute to cell movement) in cancer increases the invasive and migratory abilities of cells, and is also associated with the EMT phenomenon (33). In the present study, RKO-AS45-1 cells exhibited filopodia after everolimus treatment at $100 \mathrm{nM}$, and together with the upregulated EMT gene expression, it was hypothesized that these cells may have undergone EMT after treatment. However, only TWIST1 expression exhibited significant differences.

No significant differences in lysosomes were observed in BT-549 cells; however, analysis of the lysosomal profile revealed a significant decrease in the CTCF of RKO-AS45-1 cells and a significant increase in the CTCF of TOV-21G cells treated with everolimus compared with untreated cells. Changes in CTCF in lysosome labeling can be explained by the presence of 
the mTORC1 complex, which is a target of everolimus, on the surface of lysosomes (34). When mTORC1 is inactive, transcriptional factors translocated to the nucleus of the cells promote the expression of genes that increase lysosome catabolism, allowing the fusion with autophagosomes (34).

During the EMT, epithelial cells decrease the expression of epithelial markers such as E- and P-cadherin, and start to express mesenchymal markers such as $\mathrm{N}$-cadherin, fibronectin and vimentin (17). These changes cause morphological cellular alterations, and the cells acquire fusiform aspects characteristic of mesenchymal cells (17). According to Ribeiro and Paredes (17), the loss of P-cadherin is a particularly common event in triple-negative breast cancer cells with a CD2 $4^{\text {low }}$ and CD $44^{\text {high }}$ profile. The results of the present study confirmed that BT-549 cells exhibited a mesenchymal phenotype and metastatic characteristics, as previously described in the literature, regarding the negative $\mathrm{E} / \mathrm{P}$ cadherin and positive fibronectin profile $(35,36)$. However, in the present study, following treatment with everolimus, BT-549 cells remained negative for the epithelial marker E/P-cadherin, but positive for the mesenchymal marker fibronectin.

Chen et al (37) have demonstrated that the inhibition of the mTORC1 complex may induce hyperactivation of the mTORC2 complex, which induces the phosphorylation and activation of the AKT protein and cell proliferation. Considering that the mTORC1 protein complex is a target of everolimus (34), the results observed in the MTT assay for RKO-AS45-1 and TOV-21G in the present study may be explained by the high everolimus concentration, which may have induced hyperactivation of mTORC2, causing AKT phosphorylation and increased cell proliferation. The low survival rate of BT-549 cells may be associated with the upregulation of TGFBl after treatment with everolimus as previously reported by Zarzynska (38). In breast cancer, TGFB1 inhibits cell cycle progression and promotes apoptosis, which together contribute to the tumor suppressive effect during carcinogenesis (38).

The clonogenic assay is considered a gold standard test to evaluate the reproductive death of cells exposed to a certain treatment by their ability to form colonies (14). In cancer cells, the clonogenic ability is associated with chemotherapy sensitivity $(14,39)$. In the present study, following treatment with everolimus, the RKO-AS45-1 colonies were distanced from each other; this may have occurred due to everolimus causing alterations in the cell-cell interactions, which may be associated with the decrease in P-cadherin and increase in fibronectin expression.

Reya et al (40) have suggested that within the tumor microenvironment, there is a small cell subset with a high proliferative potency, clonogenic capacity and metastatic potential termed CSCs. These authors also suggested that chemo- or radioresistance may have enriched subpopulations of CSCs as a result of the EMT phenomenon. Thus, the high rates of surviving fraction observed in the clonogenic assay in the present study may be associated with the changes acquired during the EMT event and possibly with the presence of CSCs. Therefore, the results of the present study confirmed the association between everolimus and EMT in a manner that suggests that this drug is an EMT inducer.

The clonogenic assay was not performed using BT-549 cells in the present study as this cell line did not form colonies during the experimental protocol. This result may be explained by the absence of adhesion glycoprotein E/P-cadherin expression, which prevented the cell-cell interaction necessary for colony formation.

The TEER measurement of a cell monolayer is a sensitive and reliable method to confirm the integrity and permeability of cells (41). TEER is considered an indicator of cellular junction integrity, since low values of TEER indicate an increase in the electric current passage between cell membranes, and thus an alteration in the cell monolayer (41). In addition, TEER is a non-invasive method that can be applied to monitor living cells during various stages of growth and differentiation. In the present study, RKO-AS45-1 cells were treated with the total RNA isolated from this cell line since certain non-coding RNAs modulate cellular plasticity, interfering in different signaling pathways and leading the cells to acquire a mesenchymal phenotype, a condition related to EMT (42). Members of the TGF family serve an important role in the signaling pathways involved in cell growth, proliferation and differentiation, and ability to change the expression of cellular junction proteins, leading to the loss of cell polarity and inducing the EMT phenomenon, which has been previously described $(43,44)$. Tomei et al $(11)$ have demonstrated that $100 \mathrm{nM}$ everolimus regulates the expression of proteins associated with cell-cell interaction, such as E-cadherin and tight junction protein 1, contributing to the decrease in cell polarity and the interaction between cancer cells, which increases the possibility of metastasis.

In conclusion, the present study investigated the in vitro effects of everolimus on the EMT properties in three epithelial cancer cell lines. The BT-549 cell line has been previously described to exhibit EMT characteristics (18), whereas to the best of our knowledge, there are no reports regarding the RKO-AS45-1 and TOV-21G cell lines. The present study supported the idea that everolimus may trigger EMT in tumor cells that do not exhibit this characteristic; in addition, the results of the present study open the door to the use of a non-invasive model for evaluating and monitoring epithelial resistance in cancer cells. Therefore, further studies using human clinical samples will be conducted by our group to confirm these findings.

\section{Acknowledgements}

Not applicable.

\section{Funding}

No funding was received.

\section{Availability of data and materials}

The datasets used and/or analyzed during the current study are available from the corresponding author on reasonable request.

\section{Authors' contributions}

BOPG is responsible for the conceptualization, data collection and analysis, literature review, writing the original draft 
and revising the manuscript. WPDA, LDCB and SLF were responsible for the data collection and interpretation. LMS is the research advisor responsible for the conceptualization, data analysis, supervision and manuscript revision. All authors read and approved the final version of the manuscript.

\section{Ethics approval and consent to participate}

Not applicable.

\section{Patient consent for publication}

Not applicable.

\section{Competing interests}

The authors declare that they have no competing interests.

\section{References}

1. Tye CE, Gordon JA, Martin-Buley LA, Stein JL, Lian JB and Stein GS: Could lncRNAs be the missing links in control of mesenchymal stem cell differentiation? J Cell Physiol 230: 526-534, 2015.

2. Vella LJ: The emerging role of exosomes in epithelial-mesenchymal-transition in cancer. Fron Oncol 4: 361, 2014.

3. Xu Q, Deng F, Qin Y, Zhao Z, Wu Z, Xing Z, Ji A and Wang QJ: Long non-coding RNA regulation of epithelial-mesenchymal transition in cancer metastasis. Cell Death Dis 7: e2254, 2016.

4. Tan EJ, Olsson AK and Moustakas A: Reprogramming during epithelial to mesenchymal transition under the control of TGF $\beta$. Cell Adh Migr 9: 233-246, 2015.

5. Hajjari $M$ and Salavaty A: HOTAIR: An oncogenic long non-coding RNA in different cancers. Cancer Biol Med 12: 1-9, 2015.

6. Gutschner T and Diederichs S: The hallmarks of cancer: A long non-coding RNA point of view. RNA Biol 9: 703-719, 2012.

7. Zhang J, Zhang P, Wang L, Piao HL and Ma L: Long non-coding RNA HOTAIR in carcinogenesis and metastasis. Acta Biochim Biophys Sin 46: 1-5, 2013.

8. HurvitzSA,DalencF,Campone M,O'Regan RM,Tjan-Heijnen VC, Gligorov J, Llombart A, Jhangiani H, Mirshahidi HR, Tan-Chiu E and Miao S: A phase 2 study of everolimus combined with trastuzumab and paclitaxel in patients with HER2-overexpressing advanced breast cancer that progressed during prior trastuzumab and taxane therapy. Breast Cancer Res Treat 141: 437-446, 2013.

9. Baselga J, Semiglazov V, van Dam P, Manikhas A, Bellet M, Mayordomo J, Campone M, Kubista E, Greil R, Bianchi GS, et al: Phase II randomized study of neoadjuvant everolimus plus letrozole compared with placebo plus letrozole in patients with estrogen receptor-positive breast cancer. J Clin Oncol 27 2630-2637, 2009.

10. Ellard SL, Clemons M, Gelmon KA, Norris B, Kennecke H, Chia S, Pritchard K, Eisen A, Vandenberg T, Taylor M, et al: Randomized phase II study comparing two schedules of everolimus in patients with recurrent/metastatic breast cancer: NCIC Clinical Trials Group IND. 163. J Clin Oncol 27: 4536-4541, 2009.

11. Tomei $\mathrm{P}$, Masola V, Granata $\mathrm{S}$, Bellin $\mathrm{G}$, Carratù $\mathrm{P}$, Ficial M, Ventura VA, Onisto M, Resta O, Gambaro G, et al: Everolimus-induced epithelial to mesenchymal transition (EMT) in bronchial/pulmonary cells: When the dosage does matter in transplantation. J Nephrol 29: 881-891, 2016.

12. Masola V, Carraro A, Zaza G, Bellin G, Montin U, Violi P, Lupo A and Tedeschi U: Epithelial to mesenchymal transition in the liver field: The double face of Everolimus in vitro. BMC Gastroenterol 15: 118, 2015.

13. Livak KJ and Schmittgen TD: Analysis of relative gene expression data using real-time quantitative PCR and the 2(-Delta Delta C(T)) method. Methods 25: 402-408, 2001.

14. Mitchell PS, Parkin RK, Kroh EM, Fritz BR, Wyman SK, Pogosova-Agadjanyan EL, Peterson A, Noteboom J, O'Briant KC, Allen A, et al: Circulating microRNAs as stable blood-based markers for cancer detection. Proc Natl Acad Sci USA 105: 10513-10518, 2008.
15. Franken NA, Rodermond HM, Stap J, Haveman J and Van Bree C: Clonogenic assay of cells in vitro. Nat Protoc 1: 2315-2319, 2006.

16. Szklarczyk D, Franceschini A, Wyder S, Forslund K, Heller D, Huerta-Cepas J, Simonovic M, Roth A, Santos A, Tsafou KP, et al: STRING v10: Protein-protein interaction networks, integrated over the tree of life. Nucleic Acids Res 43 (Database Issue): D447-D452, 2015

17. Ribeiro AS and Paredes J: P-cadherin linking breast cancer stem cells and invasion: A promising marker to identify an 'intermediate/metastable' EMT state. Front Oncol 4: 371, 2014.

18. Tryndyak VP, Beland FA and Pogribny IP: E-cadherin transcriptional down-regulation by epigenetic and microRNA-200 family alterations is related to mesenchymal and drug-resistant phenotypes in human breast cancer cells. Int J Cancer 126: 2575-2583, 2010.

19. Pittenger MF, Mackay AM, Beck SC, Jaiswal RK, Douglas R, Mosca JD, Moorman MA, Simonetti DW, Craig S and Marshak DR: Multilineage potential of adult human mesenchymal stem cells. Science 284: 143-147, 1999.

20. Zhang GJ, Zhou T, Tian HP, Liu ZL and Xia SS: High expression of ZEB1 correlates with liver metastasis and poor prognosis in colorectal cancer. Oncol Lett 5: 564-568, 2013.

21. Lamouille S, Xu J and Derynck R: Molecular mechanisms of epithelial-mesenchymal transition. Nat Rev Mol Cell Biol 15: 178-196, 2014.

22. Wang MK, Sun HQ, Xiang YC, Jiang F, Su YP and Zou ZM: Different roles of TGF- $\beta$ in the multi-lineage differentiation of stem cells. World J Stem Cells 4: 28-34, 2012.

23. Mao L, Li Y, Zhao J, Li Q, Yang B, Wang Y, Zhu Z, Sun H and Zhai Z: Transforming growth factor- $\beta 1$ contributes to oxaliplatin resistance in colorectal cancer via epithelial to mesenchymal transition. Oncol Lett 14: 647-654, 2017.

24. Vu T and Datta PK: Regulation of EMT in colorectal cancer: A culprit in metastasis. Cancers 9: 171, 2017.

25. Xu Q, Wang L, Li H, Han Q, Li J, Qu X, Huang S and Zhao RC: Mesenchymal stem cells play a potential role in regulating the establishment and maintenance of epithelial-mesenchymal transition in MCF7 human breast cancer cells by paracrine and induced autocrine TGF- $\beta$. Int J Oncol 41: 959-968, 2012.

26. Wang Y, Liu J, Ying X, Lin PC and Zhou BP: Twist-mediated epithelial-mesenchymal transition promotes breast tumor cell invasion via inhibition of hippo pathway. Sci Rep 6: 24606, 2016.

27. Yusup A, Huji B, Fang C, Wang F, Dadihan T, Wang HJ and Upur H: Expression of trefoil factors and TWIST1 in colorectal cancer and their correlation with metastatic potential and prognosis. World J Gastroenterol 23: 110-120, 2017.

28. Kim YH, Kim G, Kwon CI, Kim JW, Park PW and Hahm KB: TWIST1 and SNAI1 as markers of poor prognosis in human colorectal cancer are associated with the expression of ALDH1 and TGF- 31 . Oncol Rep 31: 1380-1388, 2014.

29. Gupta RA, Shah N, Wang KC, Kim J, Horlings HM, Wong DJ, Tsai MC, Hung T, Argani P, Rinn JL, et al: Long noncoding RNA HOTAIR reprograms chromatin state to promote cancer metastasis. Nature 464: 1071-1076, 2010.

30. Breastcancer.org: Triple-Negative Breast Cancer. http://www. breastcancer.org/symptoms/diagnosis/trip_neg. Accessed October 2017.

31. Chacón RD and Costanzo MV: Triple-negative breast cancer. Breast Cancer Res 12 (Suppl 2): S3, 2010.

32. Pádua Alves C, Fonseca AS, Muys BR, de Barros E Lima Bueno R, Bürger MC, de Souza JE, Valente V, Zago MA and Silva WA Jr: Brief report: The lincRNA HOTAIR is required for epithelial-to-mesenchymal transition and stemness maintenance of cancer cell lines. Stem Cells 31: 2827-2832, 2013.

33. Amiri A, Noei F, Jeganathan S, Kulkarni G, Pinke DE and Lee JM: eEF1A2 activates Akt and stimulates Akt-dependent actin remodeling, invasion and migration. Oncogene 26: 3027-3040, 2007.

34. Puertollano R: mTOR and lysosome regulation. F1000Prime Rep 6: 52, 2014.

35. Liang YJ, Wang QY, Zhou CX, Yin QQ, He M, Yu XT, Cao DX, Chen GQ, He JR and Zhao Q: MiR-124 targets Slug to regulate epithelial-mesenchymal transition and metastasis of breast cancer. Carcinogenesis 34: 713-722, 2012.

36. Nieman MT, Prudoff RS, Johnson KR and Wheelock MJ: $\mathrm{N}$-cadherin promotes motility in human breast cancer cells regardless of their E-cadherin expression. J Cell Biol 147: 631-144, 1999. 
37. Chen BW, Chen W, Liang H, Liu H, Liang C, Zhi X, Hu LQ, Yu XZ, Wei T, Ma T, et al: Inhibition of mTORC2 induces cell-cycle arrest and enhances the cytotoxicity of doxorubicin by suppressing MDR1 expression in HCC cells. Molr Cancer Ther 14: 1805-1815, 2015.

38. Zarzynska JM: Two faces of TGF-betal in breast cancer. Mediators Inflamm 2014: 141747, 2014.

39. Browman G, Goldberg J, Gottlieb AJ, Preisler HD, Azarnia N, Priore RL, Brennan JK, Vogler WR, Winton EF, Miller KB, et al: The clonogenic assay as a reproducible in vitro system to study predictive parameters of treatment outcome in acute nonlymphoblastic leukemia. Am J Hematol 15: 227-235, 1983.

40. Reya T, Morrison SJ, Clarke MF and Weissman IL: Stem cells, cancer, and cancer stem cells. Nature 414: 105-111, 2001.

41. Srinivasan B, Kolli AR, Esch MB, Abaci HE, Shuler ML and Hickman JJ: TEER measurement techniques for in vitro barrier model systems. J Lab Autom 20: 107-126, 2015.

42. Lin CW, Lin PY and Yang PC: Noncoding RNAs in tumor epithelial-to-mesenchymal transition. Stem Cells Int 2016 $2732705,2016$.
43. Kotiyal S and Bhattacharya S: Breast cancer stem cells, EMT and therapeutic targets. Biochem Biophys Res Commun 453: 112-116, 2014.

44. Kidd M, Schimmack S, Lawrence B, Alaimo D and Modlin IM: EGFR/TGF $\alpha$ and TGF $\beta / C T G F$ signaling in neuroendocrine neoplasia: Theoretical therapeutic targets. Neuroendocrinology 97: 35-44, 2013.

(c) (7) (9) This work is licensed under a Creative Commons Attribution-NonCommercial-NoDerivatives 4.0 International (CC BY-NC-ND 4.0) License. 